TI 2012-045/1

Tinbergen Institute Discussion Paper
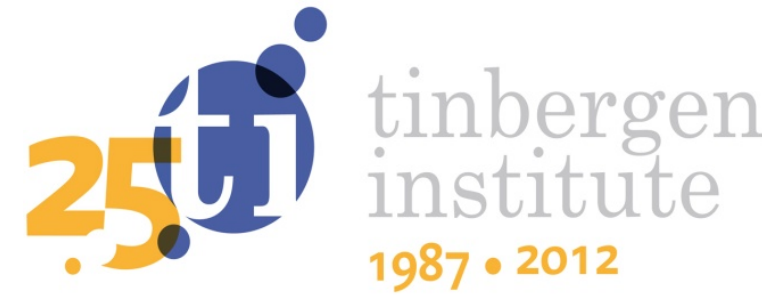

\title{
Risk and Inequality in a Social Decision Making Experiment
}

\author{
Ingrid M.T. Rohde' \\ Kirsten I.M. Rohde 2
}

' Maastricht University, Bilgi Economics Lab of Istanbul;

2 Erasmus School of Economics, Erasmus University Rotterdam, Tinbergen Institute. 
Tinbergen Institute is the graduate school and research institute in economics of Erasmus University Rotterdam, the University of Amsterdam and VU University Amsterdam.

More TI discussion papers can be downloaded at http://www.tinbergen.nl

Tinbergen Institute has two locations:

Tinbergen Institute Amsterdam

Gustav Mahlerplein 117

1082 MS Amsterdam

The Netherlands

Tel.: +31(0)205251600

Tinbergen Institute Rotterdam

Burg. Oudlaan 50

3062 PA Rotterdam

The Netherlands

Tel.: +31(0)10 4088900

Fax: $+31(0) 104089031$

Duisenberg school of finance is a collaboration of the Dutch financial sector and universities, with the ambition to support innovative research and offer top quality academic education in core areas of finance.

DSF research papers can be downloaded at: http://www.dsf.nl/

Duisenberg school of finance

Gustav Mahlerplein 117

1082 MS Amsterdam

The Netherlands

Tel.: +31(0)20 5258579 


\title{
Risk and Inequality in a Social Decision Making Experiment*
}

\author{
Ingrid M.T. Rohde $\quad$ Kirsten I.M. Rohde ${ }^{\ddagger} \S$
}

April 24, 2012

\begin{abstract}
As societies are increasingly concerned with social risks, it is important to evaluate risks not only from an individual perspective, but also from a societal one. Many increases in social risk involve a simultaneous increase in risk and inequality. This paper presents an experiment which disentangles concerns for risk and inequality in a social risk context. Subjects choose between different types of allocations of risks over 10 other participants. The allocations differ only in terms of dispersion. We disentangle four types of dispersion: ex ante inequality, ex post inequality, individual risk, and collective risk. The results show that people are averse towards ex ante inequality and individual risk, whereas they are ex post inequality and collective risk seeking.
\end{abstract}

*Kirsten Rohde's research was made possible through a VENI grant from the Netherlands Organization for Scientific Research (NWO). Erasmus Research Institute of Management provided financial support. We thank Kristof Bosmans and participants of the EIPE seminar at Erasmus University Rotterdam for helpful comments.

${ }^{\dagger}$ Maastricht University, the Netherlands, and Bilgi Economics Lab of Istanbul (BELIS), Murat Sertel Center for Advanced Economic Studies, Istanbul Bilgi University, Dolapdere Campus Kurtuluş Deresi Cad. No: 47 Istanbul 34440, Turkey (e-mail: ingridmtrohde@gmail.com)

${ }^{\ddagger}$ Erasmus School of Economics, H13-25, Erasmus University Rotterdam, P.O. Box 1738, 3000 DR

Rotterdam, the Netherlands. E-mail: rohde@ese.eur.nl

$\S$ Tinbergen Institute, the Netherlands 


\section{Introduction}

Societies are increasingly concerned with social risks such as health epidemics, acts of terrorism, and climate change. One reason for this increased preoccupation is that these risks possibly affect many members of society at the same time. It is therefore important to evaluate the allocation of such risks not only from an individual, but also from a broad societal perspective. Two essential dimensions of such social risks are the inequality concerning the distribution of risks over various groups and members of society and the level of risk faced by individuals and by the society as a whole.

Two notions of inequality are critical when evaluating distributions of risk across society (Diamond 1967 and Harsanyi 1955): first, ex-ante inequality, which concerns the procedure that generates the distributions, and second, ex-post inequality, which concerns the eventual distribution of outcomes (Fleurbaey 2010, Sarin 1985, Trautmann 2009). The literature on public risk (Fishburn and Sarin 1991, Keeney 1980, Keeney and Winkler 1985, Sarin 1985, Gajdos, Weymark, and Zoli 2010) indicates that, next to inequalities, the possible aggregate payoffs of the group or society also plays a role in decisions to allocate risks over society. Therefore, we consider two levels of risk: individual risk and collective risk. Individual risk refers to the dispersion of the possible outcomes for one individual, neglecting the outcomes of others. Collective risk refers to the dispersion of the total sum of outcomes.

Consider a group of individuals and the following two possible allocations of risk. In allocation A each individual receives an independent lottery yielding $€ 20$ with $50 \%$ probability and nothing otherwise. In allocation B 50\% of the individuals receive $€ 20$ and the others nothing, where the $50 \%$ fortunate ones are predetermined by a certain characteristic of the individuals, such as age. Which allocation would be considered to be socially superior? Should we give everyone an equal opportunity or should we favor particular groups in society? Allocation A, which is in line with the notion of equality of opportunity, could be regarded as superior as all individuals face equal chances. From the perspective of solidarity, though, one might argue that it is favorable to support the weakest in society 
such as children and the elderly, which will lead to predetermined allocations, as is the case in allocation B. This conflict between equality of opportunity and solidarity is present in many real life situations such as allocation of donor organs, student placement procedures, the allocation of power plants, and the design of rescue plots in case of calamities.

Now suppose that allocation B is replaced by allocation C, where with a $50 \%$ probability all individuals receive $€ 20$ and otherwise all individuals receive nothing. This allocation $\mathrm{C}$ guarantees that everyone receives the same outcome but does not take away the uncertainty whether this outcome will be high or not. In both allocations $\mathrm{A}$ and $\mathrm{C}$, each individual has a $50 \%$ probability to win $€ 20$ and a $50 \%$ probability to win nothing. Therefore, one can argue that in both allocations individuals face this lottery. What distinguishes the allocations is the resulting inequality after resolution of uncertainty: in allocation $\mathrm{C}$ there is no inequality, whereas in allocation $\mathrm{A}$ it is very likely that there will be inequality.

Whether or not a person finds allocations $\mathrm{A}$ and $\mathrm{C}$ different from each other, depends partly on the order in which he processes risks and inequalities. A person primarily focussed on ex ante inequality and thereby first processing risk and then inequality may argue that in both allocation procedures all individuals get the same lottery and thereby, have the same chances, i.e. equal opportunities, so that there is no inequality. This person will find both procedures equivalent. A person primarily focussed on ex post inequality and thereby first processing inequalities and then risk, may argue that in allocation $\mathrm{C}$ there will always be equality after resolution of the uncertainty, whereas in allocation $\mathrm{A}$ it is very likely that there will be inequality after resolution of uncertainty. This person will not find the two procedures equivalent. Thus, the order in which the two types of dispersion, inequality and risk, are processed, affects preferences and, thereby, also sheds light on people's concern for procedural fairness.

In this paper we experimentally investigate individuals' attitudes towards social risks. Subjects are confronted with various procedures to allocate risks, which differ only in terms of the four types of dispersion concerning risk and inequality. All procedures have equal expected values.

Though many studies have analyzed people's concerns for risk, and many have analyzed 
people's concerns for inequality, only very few have studied how concerns for risk and inequality are integrated (Bolton, Brandts, and Ockenfels 2005, Kroll and Davidovitz 2003, Keller and Sarin 1988, Bian and Keller 1999). This paper is the first to disentangle the four risk and inequality concerns through an experiment with real incentives. Our experiment is inspired by a previous study (Rohde and Rohde 2011) where we found that subjects had a strong preference for an allocation rule which gave every individual the same independent risk, such as allocation rule $\mathrm{A}$ in the previous example, while subjects were reluctant to implement allocation rules which favored a randomly selected, predetermined number of individuals. The current paper provides insights into the reason for this preference.

The results of the experiment are striking. We observe a clear pattern in individuals' preferences over different allocation procedures. Moreover, we find that people are averse towards ex ante inequality and individual risk, while they seek ex post inequality and collective risk. We will argue that these results are in line with Engelmann and Strobel (2004) who, in a riskless setting, found that inequality aversion was mostly driven by other basic concerns like maximin preferences.

\section{Risk and Inequality}

We consider a setting with $n+1$ individuals $0, \ldots, n$. Individual 0 is the social decision maker (SDM) whose preferences we are interested in. The social decision maker chooses between distributions of risk for the $n$ other players and thereby acts as a social planner. His own payoff is unaffected by his decisions. Our setting thereby resembles a public risk setting (Keeney, 1980) with the only difference being that the outcomes we consider are continuous monetary payoffs instead of binary outcomes such as life or death.

In order to structure this paper, we need to introduce a few formal definitions. An $e x$ post allocation $\mathbf{x}=\left(x_{1}, \ldots, x_{n}\right)$ yields outcome $x_{i} \in \mathbb{R}$ to individual $i$ and thereby specifies a payoff to all individuals except for the decision maker whose payoff is always unaffected. An ex ante allocation $\mathbf{L}=\left(p_{1}: \mathbf{x}_{1}, \ldots, p_{m}: \mathbf{x}_{m}\right)$ for any finite $m$ yields ex post allocation $\mathbf{x}_{j}$ with probability $p_{j}$ for $j=1, \ldots, m$. An ex post allocation is an allocation that results 
after risk is resolved. An ex ante allocation is a lottery of ex post allocations and thereby describes the probabilities that particular ex post allocations may result.

In this paper we analyze preferences over ex ante allocations. Two important motives that are likely to drive these preferences are inequality aversion and risk aversion. The experiment in this paper is designed to isolate these motives from others by keeping expected values constant, as will become clear in Section 3. In line with the literature, we consider two types of inequality: ex ante inequality and expected ex post inequality.

The individual expected value of individual $i$ in ex ante allocation $\mathbf{L}=\left(p_{1}: \mathbf{x}_{1}, \ldots, p_{m}\right.$ : $\left.\mathbf{x}_{m}\right)$ is defined by $I E V_{i}(\mathbf{L})=\sum_{j=1}^{m} p_{j} x_{i, j}$. The average expected value of ex ante allocation $\mathbf{L}$ is then given by $\overline{I E V}(\mathbf{L})=\sum_{i=1}^{n} \frac{1}{n} I E V_{i}(\mathbf{L})$. We define ex ante inequality as the standard deviation ${ }^{1}$ of the distribution of individual expected values: $E A I(\mathbf{L})=$ $\sqrt{\sum_{i=1}^{n} \frac{1}{n}\left(I E V_{i}(\mathbf{L})-\overline{I E V}(\mathbf{L})\right)^{2}}$.

The ex post average payoff of ex post allocation $\mathbf{x}=\left(x_{1}, \ldots, x_{n}\right)$ is given by $\overline{\mathbf{x}}=$ $\sum_{i=1}^{n} \frac{1}{n} x_{i}$. The ex post inequality of ex post allocation $\mathbf{x}=\left(x_{1}, \ldots, x_{n}\right)$ is the standard deviation of the ex post distribution and is given by $\operatorname{EPI}(\mathbf{x})=\sqrt{\sum_{i=1}^{n} \frac{1}{n}\left(x_{i}-\overline{\mathbf{x}}\right)^{2}}$. The expected ex post inequality of ex ante allocation $\mathbf{L}=\left(p_{1}: \mathbf{x}_{1}, \ldots, p_{m}: \mathbf{x}_{m}\right)$ is given by $\operatorname{EEPI}(\mathbf{x})=\sum_{j=1}^{m}\left(p_{j} \operatorname{EPI}\left(\mathbf{x}_{j}\right)\right)$.

In line with the literature on public risk, we also consider two types of risk: individual risk and collective risk. The individual risk of individual $i$ in ex ante allocation $\mathbf{L}=\left(p_{1}\right.$ : $\left.\mathbf{x}_{1}, \ldots, p_{m}: \mathbf{x}_{m}\right)$ is defined by $I R_{i}(\mathbf{L})=\sqrt{\sum_{j=1}^{m} p_{j}\left(x_{i, j}-I E V_{i}(\mathbf{L})\right)^{2}}$. We define collective risk as the standard deviation of the total payoff that accrues to the group of individuals $1, \ldots n$. The collective expected value of ex ante allocation $\mathbf{L}=\left(p_{1}: \mathbf{x}_{1}, \ldots, p_{m}: \mathbf{x}_{m}\right)$ is defined by $C E V(\mathbf{L})=\sum_{j=1}^{m} p_{j}\left(\sum_{i=1}^{n} x_{i, j}\right)$. The collective risk of ex ante allocation $\mathbf{L}=\left(p_{1}: \mathbf{x}_{1}, \ldots, p_{m}: \mathbf{x}_{m}\right)$ is defined by $C R(\mathbf{L})=\sqrt{\sum_{j=1}^{m} p_{j}\left(\left(\sum_{i=1}^{n} x_{i, j}\right)-C E V(\mathbf{L})\right)^{2}}$.

We will say that the social decision maker is ex ante inequality averse if he strictly prefers ex ante allocations with lower ex ante inequality, everything else held constant.

\footnotetext{
${ }^{1}$ We choose to operationalize both risk and inequality by using the standard deviation. Other inequality measures such as the Gini index and the Theil index did not affect the results qualitatively. Therefore, we only report the results based on standard deviations.
} 
We will say that he is ex ante inequality seeking if he strictly prefers ex ante allocations with higher ex ante inequality, everything else held constant. And finally, we will say that he is ex ante inequality neutral if ex ante inequality does not play any role in his preferences. Aversion, neutrality, and seeking are defined in a similar way for ex post inequality, individual risk, and collective risk .

\section{Allocation Types}

In an experiment we disentangle attitudes towards risks and inequalities by letting subjects make pairwise choices between several allocation types. We let $n$ equal 10 so that there are 11 participants per session $(10+$ the decision maker). Let $(50 \%: 10,50 \%: 5)$ denote a Basic Lottery that yields $€ 10$ with $50 \%$ probability and $€ 5$ otherwise. From such a basic lottery we derive five allocation types. To enhance readability, the phrases 'all individuals' and 'all subjects' will from now on refer to all individuals except the decision maker. The different allocation types are as follows:

\section{- Independent Lottery (50\%: 10,50\%: 5)}

All individuals independently receive the lottery $(50 \%: 10,50 \%: 5)$, i.e. this lottery is resolved 10 times.

- Common Lottery (50\%: 10,50\%: 5)

The lottery $(50 \%: 10,50 \%: 5)$ is resolved once and all 10 individuals receive the same outcome of the lottery.

\section{- Random Distribution (5:10, 5:5)}

Half $(50 \%)$ of the 10 individuals are randomly selected and receive $€ 10$ while the others receive $€ 5$. All individuals have equal probability of being selected to receive the larger outcome.

\section{- IDbased Distribution (5:10, 5:5)}

Half $(50 \%)$ of the 10 individuals are selected based on their ID number and receive 
$€ 10$ while the others receive $€ 5$.

- Common Outcome (10:7.5)

All individuals receive $€ 7.50$.

Table 1(a) summarizes these five allocation types regarding the degree of risks and inequalities. Pairwise comparisons between these lotteries allow us to disentangle concerns for risks and inequalities. Consider, for instance, the choice between a Random Distribution and the corresponding IDbased Distribution. These allocations differ in only one respect: in the Random Distribution the social planner does not know up front who will receive which outcome, while in the IDbased Distribution the social planner does. Thus, the IDbased Distribution imposes a larger ex ante inequality than the Random Distribution, but the same expected ex post inequality and risk. A preference between these allocations therefore directly reveals the attitude towards ex ante inequality.

The Random Distribution differs from the corresponding Common Lottery in two respects: the Random Distribution imposes a larger expected ex post inequality, whereas the Common Lottery imposes a larger collective risk. Therefore, a preference between these two allocations gives information about the attitudes towards ex post inequality and collective risk. If, for instance, a person is collective risk averse and prefers the Common Lottery to the Random Distribution then he must be expected ex post inequality averse. A preference between the Random Distribution and the corresponding Independent Lottery similarly reveals attitudes towards ex post inequality and collective risk. The Common Outcome then allows us to reveal the attitude towards individual risk.

\section{Experimental Design}

In the experiment we consider three basic lotteries: $(50 \%: 10,50 \%: 5),(20 \%: 11.5,80 \%$ : 6.5), and $(30 \%: 4,70 \%: 9)$, where the outcomes are in terms of Euro. Each lottery has an expected value of $€ 7.5$. In every lottery the absolute difference between the highest and lowest outcome is $€ 5$. The lotteries differ in the relative chances of obtaining the high 
(a) Basic Lottery (50\%:10, 50\%:5)

\begin{tabular}{l|c|c|c|c|}
\multicolumn{2}{c}{ Inequality } & \multicolumn{2}{c}{ Risk } \\
\cline { 2 - 5 } & Ex ante & Expected ex post & Individual & Collective \\
\cline { 2 - 5 } Independent Lottery & 0 & 2.36 & 2.50 & 7.91 \\
\cline { 2 - 5 } Common Lottery & 0 & 0 & 2.50 & 25.00 \\
\cline { 2 - 5 } $\begin{array}{l}\text { Common Outcome } \\
\text { Random Distribution }\end{array}$ & 0 & 0 & 0 & 0 \\
\cline { 2 - 5 } IDbased Distribution & 0 & 2.50 & 2.50 & 0 \\
\cline { 2 - 5 } & 2.50 & 2.50 & 2.50 & 0 \\
\cline { 2 - 5 } & & & &
\end{tabular}

(b) Basic Lottery (20\%:11.5, 80\%:6.5)

\begin{tabular}{l|c|c|c|c|}
\multicolumn{1}{c}{} & \multicolumn{1}{c}{ Ex ante } & Expected ex post & \multicolumn{1}{c}{ Individual } & \multicolumn{1}{c}{ Collective } \\
\cline { 2 - 5 } Independent Lottery & 0 & 1.77 & 2.00 & 6.32 \\
\cline { 2 - 5 } Common Lottery & 0 & 0 & 2.00 & 20.00 \\
\cline { 2 - 5 } Common Outcome & 0 & 0 & 0 & 0 \\
\cline { 2 - 5 } $\begin{array}{l}\text { Random Distribution } \\
\text { IDbased Distribution }\end{array}$ & 0 & 2.00 & 2.00 & 0 \\
\cline { 2 - 5 } & 2.00 & 2.00 & 2.00 & 0 \\
\cline { 2 - 5 } & & &
\end{tabular}

(c) Basic Lottery (30\%:4, 70\%:9)

\begin{tabular}{l|c|c|c|c|}
\multicolumn{1}{c}{} & \multicolumn{1}{c}{ Ex ante } & Expected ex post & \multicolumn{1}{c}{ Individual } & \multicolumn{1}{c}{ Collective } \\
\cline { 2 - 5 } Independent Lottery & 0 & 2.12 & 2.29 & 7.25 \\
\cline { 2 - 5 } Common Lottery & 0 & 0 & 2.29 & 22.91 \\
\cline { 2 - 5 } Common Outcome & 0 & 0 & 0 & 0 \\
\cline { 2 - 5 } $\begin{array}{l}\text { Random Distribution } \\
\text { IDbased Distribution }\end{array}$ & 0 & 2.29 & 2.29 & 0 \\
\cline { 2 - 5 } & 2.29 & 2.29 & 2.29 & 0 \\
\cline { 2 - 5 }
\end{tabular}

Table 1: Values of the inequality and risk measures for each of the allocation types. 
outcome. In lottery $(20 \%: 11.5,80 \%: 6.5)$ the chance of receiving the high outcome is relatively low, whereas in lottery $(30 \%: 4,70 \%: 9)$ this chance is relatively high.

For each of the three basic lotteries we derive the five different allocation types as described in the previous section. Subjects make pairwise choices between these allocations, resulting in 3 times 10 binary choices as summarized in Table 2. Thus, the choices subjects make are choices between allocations types that are based on the same basic lottery. We repeat these choices for different basic lotteries.

For each of the three basic lotteries and for each allocation type, Table 1 gives the values of the risks and inequalities. In the IDbased Distribution subjects are selected based on their student ID number. At the start of the experiment all subjects have to give their student ID number to the experimenter. The experimenter takes the sum of all digits in the student ID number and the ones with the lowest sums will receive the highest outcomes. In case of two students having the same sum of digits, the lower student ID number yields the higher outcome. In this allocation type we compute ex ante inequality assuming that the social decision maker knows the sum of digits of each participant's student ID numbers. For individual risk in the IDbased Distribution we assume that the social decision maker places himself in the position of the individuals, who do not know the sum of digits of the student ID numbers of the other participants.

At the end of the session we randomly choose one of the subjects to be the social decision maker and randomly choose one of his questions to determine what the payoff of every subject would be. No matter which ex ante allocation the social decision maker chooses, he receives $€ 7.50$ for participating. In all questions the individual expected values for each of the participants are equal to $€ 7.50$. In addition to these earnings all subjects receive $€ 5.00$ for participating. Therefore, preferences cannot not be driven by differences in individual expected values. 


\subsection{Subjects, payment, and procedures}

We recruited 55 undergraduate students from Erasmus University Rotterdam (34 male, 21 female, 52 economics students) for 5 sessions of 11 subjects. All participants were recruited using ORSEE (Greiner, 2004). Each subject participated in one only session. To ensure anonymity and avoid communication during the experiment, subjects were seated in sightshielded cubicles. After being seated, subjects received written instructions, which they could study at their own pace. They could ask questions privately in case they needed clarification. The experiment did not start before all subjects had correctly answered a series of comprehension questions. The instructions and comprehension questions are in the Appendix.

The experiment was computerized using Z-tree (Fischbacher, 2007). Every question was displayed in a different screen, where one option was shown on the left-hand side and the other on the right-hand side. We randomized the order of the questions and the left/right position of the options. The experiment started with 3 practice questions, where each of the allocation types was an option at least once. The allocation types in these practice questions were based on different basic lotteries than the other questions of the experiment.

\section{Results}

The results of our experiment are analyzed in two stages. In the first stage we start with several non-parametric analyzes. In the second stage we employ logit regressions to further analyze the data. All tests reported in this section are two-sided, unless stated differently.

\subsection{Attitudes towards Risk and Inequality}

Table 2 (fourth column) shows, for each question, the percentage of subjects choosing option A. If choices were completely random then the percentage of subjects choosing option A would be $50 \%$, as the order in which the options are presented is randomized. 
The last column of the table gives the two-sided p-values of binomial tests with assumed probability 50\%. For each question a separate binomial test was done. We repeated these binomial tests for data pooled by question type, independently of the basic lottery. These results are summarized in Table 3. For instance, we combined all choices between independent lotteries and random distributions, no matter which underlying basic lottery, i.e. we combined questions 1,11 , and 21 .

From the pooled data we conclude that, on average, subjects have the following preferences over allocation types:

IndepLottery $\sim$ CommonOutcome $\succ$ CommonLottery $\succ$ RandomDistr $\succ$ IDbasedDistr

where each of the strict preferences indicates significance at the $5 \%$ level, except for the common outcome being preferred to the common lottery, which has a pooled p-value of 0.119 .

When looking at the data per question, we see that the independent lottery is preferred over the common lottery, but not significantly. Yet, the pooled data show a significance. The common outcome is significantly preferred over the common lottery only for the basic lottery (30\%:4,7\%:9). For the remaining questions, a few significance levels are lower than in the pooled data, but there are no strong contradictions of the abovementioned preference pattern.

For every subject we counted the number of choices that are in line with the general pattern described above. These counts are summarized in Figure 1. A binomial test shows that significantly more than $50 \%$ of the subjects (37 out of 55) are consistent with this pattern in at least two third of their choices (p-value $=0.003$ ). The results so far are consistent with the findings of Keller and Sarin (1988) and Bian and Keller (1999), who did surveys asking people to choose between some of our allocation types in health and safety contexts. Kroll and Davidovitz (2003), however, found that 8-year-old children prefer a common lottery to the corresponding independent lottery.

Interpretation of the Results For the interpretation of the results we assume that 


\begin{tabular}{|c|c|c|c|c|c|}
\hline & Option A & Option B & $\mathbf{A}$ & B & p-value \\
\hline 1 & Independent Lottery $(50 \%: 10,50 \%: 5)$ & Random Distribution $(5: 10,5: 5)$ & $78 \%$ & $22 \%$ & $0.000^{* * *}$ \\
\hline 2 & Independent Lottery $(50 \%: 10,50 \%: 5)$ & IDbased Distribution $(5: 10,5: 5)$ & $75 \%$ & $25 \%$ & $0.000^{* * *}$ \\
\hline 3 & Independent Lottery $(50 \%: 10,50 \%: 5)$ & Common Lottery $(50 \%: 10,50 \%: 5)$ & $60 \%$ & $40 \%$ & 0.177 \\
\hline 4 & Independent Lottery $(50 \%: 10,50 \%: 5)$ & Common Outcome 7.50 & $55 \%$ & $45 \%$ & 0.590 \\
\hline 5 & Random Distribution $(5: 10,5: 5)$ & IDbased Distribution $(5: 10,5: 5)$ & $65 \%$ & $35 \%$ & $0.030^{* *}$ \\
\hline 6 & Random Distribution $(5: 10,5: 5)$ & Common Lottery $(50 \%: 10,50 \%: 5)$ & $40 \%$ & $60 \%$ & 0.177 \\
\hline 7 & Random Distribution $(5: 10,5: 5)$ & Common Outcome 7.50 & $35 \%$ & $65 \%$ & $0.030 * *$ \\
\hline 8 & IDbased Distribution $(5: 10,5: 5)$ & Common Lottery $(50 \%: 10,50 \%: 5)$ & $35 \%$ & $65 \%$ & $0.030^{* *}$ \\
\hline 9 & IDbased Distribution $(5: 10,5: 5)$ & Common Outcome 7.50 & $35 \%$ & $65 \%$ & $0.030 * *$ \\
\hline 10 & Common Lottery $(50 \%: 10,50 \%: 5)$ & Common Outcome 7.50 & $47 \%$ & $53 \%$ & 0.788 \\
\hline 11 & Independent Lottery $(20 \%: 11.5,80 \%: 6.5)$ & Random Distribution $(2: 11.5,8: 6.5)$ & $76 \%$ & $24 \%$ & $0.000^{* * *}$ \\
\hline 12 & Independent Lottery $(20 \%: 11.5,80 \%: 6.5)$ & IDbased Distribution $(2: 11.5,8: 6.5)$ & $84 \%$ & $16 \%$ & $0.000^{* * *}$ \\
\hline 13 & Independent Lottery $(20 \%: 11.5,80 \%: 6.5)$ & Common Lottery (20\%:11.5, 80\%:6.5) & $58 \%$ & $42 \%$ & 0.281 \\
\hline 14 & Independent Lottery $(20 \%: 11.5,80 \%: 6.5)$ & Common Outcome 7.50 & $44 \%$ & $56 \%$ & 0.419 \\
\hline 15 & Random Distribution $(2: 11.5,8: 6.5)$ & IDbased Distribution $(2: 11.5,8: 6.5)$ & $76 \%$ & $24 \%$ & $0.000^{* * *}$ \\
\hline 16 & Random Distribution $(2: 11.5,8: 6.5)$ & Common Lottery (20\%:11.5, 80\%:6.5) & $35 \%$ & $65 \%$ & $0.030 * *$ \\
\hline 17 & Random Distribution $(2: 11.5,8: 6.5)$ & Common Outcome 7.50 & $38 \%$ & $62 \%$ & 0.105 \\
\hline 18 & IDbased Distribution $(2: 11.5,8: 6.5)$ & Common Lottery (20\%:11.5, 80\%:6.5) & $38 \%$ & $62 \%$ & 0.105 \\
\hline 19 & IDbased Distribution $(2: 11.5,8: 6.5)$ & Common Outcome 7.50 & $33 \%$ & $67 \%$ & $0.014^{* *}$ \\
\hline 20 & Common Lottery (20\%:11.5, 80\%:6.5) & Common Outcome 7.50 & $51 \%$ & $49 \%$ & 1.000 \\
\hline 21 & Independent Lottery $(30 \%: 4,70 \%: 9)$ & Random Distribution $(3: 4,7: 9)$ & $64 \%$ & $36 \%$ & $0.058^{*}$ \\
\hline 22 & Independent Lottery $(30 \%: 4,70 \%: 9)$ & IDbased Distribution $(3: 4,7: 9)$ & $73 \%$ & $27 \%$ & $0.001^{* * *}$ \\
\hline 23 & Independent Lottery $(30 \%: 4,70 \%: 9)$ & Common Lottery $(30 \%: 4,70 \%: 9)$ & $56 \%$ & $44 \%$ & 0.419 \\
\hline 24 & Independent Lottery $(30 \%: 4,70 \%: 9)$ & Common Outcome 7.50 & $44 \%$ & $56 \%$ & 0.419 \\
\hline 25 & Random Distribution $(3: 4,7: 9)$ & IDbased Distribution $(3: 4,7: 9)$ & $62 \%$ & $38 \%$ & 0.105 \\
\hline 26 & Random Distribution $(3: 4,7: 9)$ & Common Lottery $(30 \%: 4,70 \%: 9)$ & $44 \%$ & $56 \%$ & 0.419 \\
\hline 27 & Random Distribution $(3: 4,7: 9)$ & Common Outcome 7.50 & $36 \%$ & $64 \%$ & $0.058^{*}$ \\
\hline 28 & IDbased Distribution $(3: 4,7: 9)$ & Common Lottery $(30 \%: 4,70 \%: 9)$ & $36 \%$ & $64 \%$ & $0.058^{*}$ \\
\hline 29 & IDbased Distribution $(3: 4,7: 9)$ & Common Outcome 7.50 & $36 \%$ & $64 \%$ & $0.058^{*}$ \\
\hline 30 & Common Lottery $(30 \%: 4,70 \%: 9)$ & Common Outcome 7.50 & $33 \%$ & $67 \%$ & $0.014^{* *}$ \\
\hline
\end{tabular}

Table 2: Questions of the experiment. 


\begin{tabular}{|l|l|l|l|l|l|}
\hline & Option A & Option B & A & B & p-value \\
\hline \hline $1 \& 11 \& 21$ & Independent lottery & Random distribution & $\mathbf{7 3 \%}$ & $27 \%$ & $0.000^{* * *}$ \\
\hline $2 \& 12 \& 22$ & Independent lottery & IDbased distribution & $\mathbf{7 7 \%}$ & $23 \%$ & $0.000^{* * *}$ \\
\hline $3 \& 13 \& 23$ & Independent lottery & Common Lottery & $\mathbf{5 8 \%}$ & $42 \%$ & $0.043^{* *}$ \\
\hline $4 \& 14 \& 24$ & Independent lottery & Common outcome & $47 \%$ & $53 \%$ & 0.534 \\
\hline $5 \& 15 \& 25$ & Random distribution & IDbased distribution & $\mathbf{6 8 \%}$ & $32 \%$ & $0.000^{* * *}$ \\
\hline $6 \& 16 \& 26$ & Random distribution & Common Lottery & $39 \%$ & $\mathbf{6 1 \%}$ & $0.008^{* * *}$ \\
\hline $7 \& 17 \& 27$ & Random distribution & Common outcome & $36 \%$ & $\mathbf{6 4 \%}$ & $0.001^{* * *}$ \\
\hline $8 \& 18 \& 28$ & IDbased distribution & Common Lottery & $36 \%$ & $\mathbf{6 4 \%}$ & $0.001^{* * *}$ \\
\hline $9 \& 19 \& 29$ & IDbased distribution & Common outcome & $35 \%$ & $\mathbf{6 5 \%}$ & $0.000^{* * *}$ \\
\hline $10 \& 20 \& 30$ & Common Lottery & Common outcome & $44 \%$ & $56 \%$ & 0.119 \\
\hline
\end{tabular}

Table 3: Data pooled by question type independently of basic lottery.

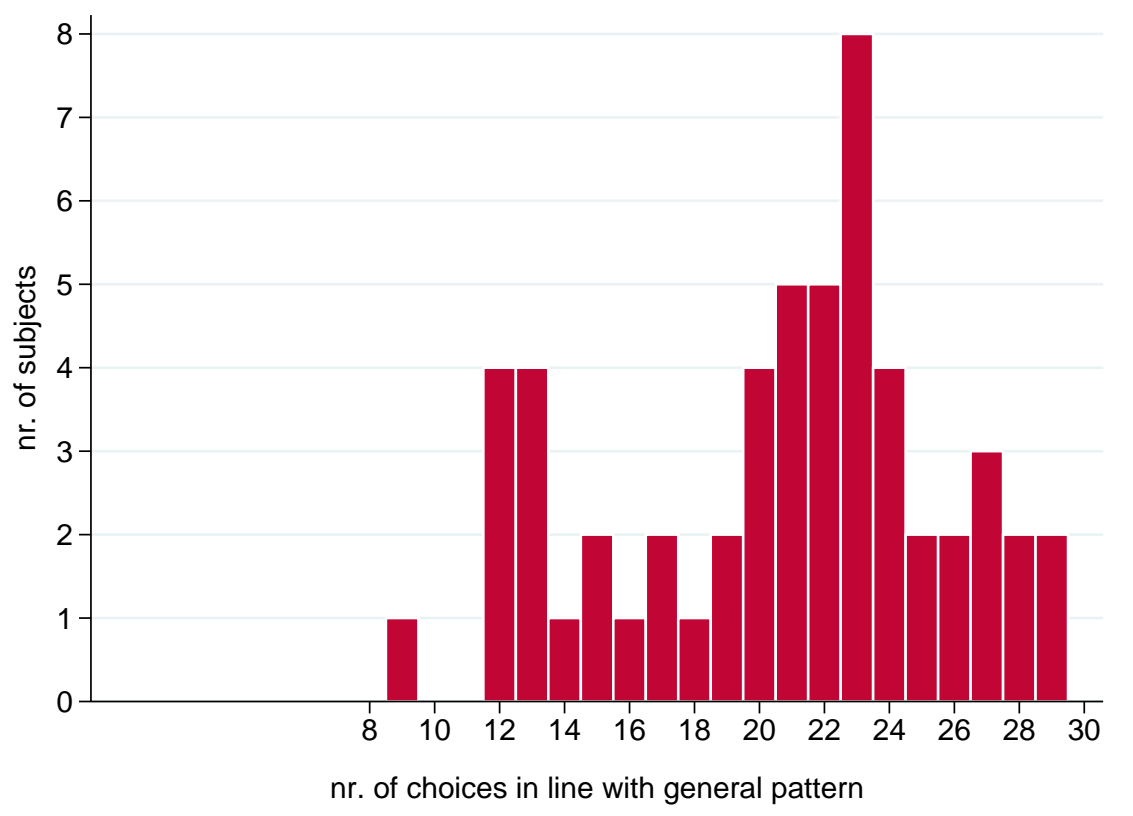

Figure 1: Summary of consistency with the general pattern

decision makers have consistent preferences in the sense that if they are averse (seeking or neutral) to a risk or inequality concept in one decision situation, they are so in all decision situations. The preference for the Random Distribution over the IDbased Distribution is 
highly significant. Looking at Table 1 we see that the only difference between these two allocation types is the ex ante inequality. Thus, we can conclude that subjects are ex ante inequality averse.

From the preference for the Common Lottery over the Random Distribution we conclude that if people are expected ex post inequality seeking or neutral, then they must be collective risk seeking. If they are collective risk averse or neutral, then they must be expected ex post inequality averse. The preference for the Independent Lottery over the Common Lottery indicates that if people are expected ex post inequality averse or neutral, then they must be collective risk averse. If they are collective risk seeking or neutral, then they must be expected ex post inequality seeking.

From the preference for the Common Outcome over the Random Distribution we see that if people are expected ex post inequality seeking or neutral, then they must be individual risk averse. Similarly, from the preference for the Common Outcome over the Common Lottery we can conclude that if people are collective risk seeking or neutral, then they must be individual risk averse. Finally, from the indifference between the Independent Lottery and the Common Outcome we can then conclude that people must be expected ex post inequality seeking, individual risk seeking, or collective risk seeking.

To summarize, of the $3^{4}=81$ theoretically possible combinations of inequality and risk attitudes, 2 are consistent with the findings:

(I) ex ante inequality averse - ex post inequality averse - individual risk seeking - collective risk averse

(II) ex ante inequality averse - ex post inequality seeking - individual risk averse - collective risk seeking

\subsection{Relative importance of risk and inequality}

In order to determine which of the two combinations of attitudes towards inequality and risk is most consistent with the data, we employ a logit estimation. For every allocation type $j$ we let ante $_{j}$, post $_{j}$, ind $_{j}$, and $\operatorname{coll}_{j}$ denote its ex ante inequality, expected ex post 
inequality, individual risk, and collective risk, respectively. We assume that the evaluation of an allocation type is based on a weighted sum of these motives, i.e. the value of allocation $j$ for individual $i$ is given by

$$
V_{i, j}=\gamma_{a n t e} \text { ante }_{j}+\gamma_{\text {post }} \text { post }_{j}+\gamma_{\text {ind }} \text { ind }_{j}+\gamma_{\text {coll }} \text { coll }_{j}+\varepsilon_{i, j}
$$

where $\varepsilon_{i, j}$ is an individual-specific error term. Then the probability that an individual chooses allocation $j$ when he is offered the choice between allocation $j$ and allocation $k$, is given by

$$
P\left(V_{i, j}>V_{i, k}\right)=\frac{\exp \left(V_{i, j}-V_{i, k}\right)}{1+\exp \left(V_{i, j}-V_{i, k}\right)} .
$$

We estimate the coefficients $\gamma_{\text {ante }}, \gamma_{\text {post }}, \gamma_{\text {ind }}$, and $\gamma_{\text {coll }}$, by using robust variance estimators clustered by subject. Thereby we correct for possible differences in behavior between subjects.

Table 4 reports the estimated odds ratios and their p-values for the coefficients. Rows 2 till 5 of the table show that all motives play a highly significant role. The odds ratios show that people are ex ante inequality averse, ex post inequality seeking, individual risk averse, and collective risk seeking. One may wonder whether the high significant levels may be due to the fact that we assume the responses to different questions to be independent, whereas this independence may be violated if subjects make transitive choices. Therefore, we also ran the same regression including only the responses to questions $1,5,8,10,11$, $15,18,20,21,25,28$, and 30. Qualitatively, the results of this regression are the same as for the regression with all data: same attitudes towards the motives and equally high significance.

At first sight it is counterintuitive and thereby surprising to see that people are ex post inequality seeking and collective risk seeking. Yet, by having a closer look at expected ex post inequality and collective risk these findings can be reconciled with our intuition as follows. Keeney (1980) and Ben-Porath, Gilboa, and Schmeidler (1997) showed that collective risk seeking is closely related to ex post inequality aversion. They show that when omitting collective risk, collective risk seeking is translated into ex post inequality aversion. Thus, when not properly accounting for collective risk, the usual finding of ex 
post inequality aversion could, theoretically, be the net result of a combination of two pure attitudes: pure ex post inequality seeking and pure collective risk seeking. In order to investigate whether this is the case for our data, we also ran logit regressions with only one motive at a time.

The results are reported in rows 6 till 9 of Table 4 . There we see that if we only focus on ex ante inequality, we find significant aversion, which is in line with our previous estimation. Similarly, we find individual risk aversion if we isolate that motive. We find collective risk seeking, which is also in line with previous estimations. Yet, when only incorporating ex post inequality, we find significant ex post inequality aversion. Thus, if we do not properly account for collective risk, collective risk seeking is translated into ex post inequality aversion, resulting in a net effect of ex post inequality aversion when combined with pure ex post inequality seeking. This is an interesting result, which shows that inequality is a complex concept that should be interpreted with care. The results are in line with Engelmann and Strobel (2004) who, in a riskless setting, also found that inequality aversion was mostly driven by other basic concerns like maximin preferences.

Finally, we ran logit regressions including only the inequality measures (rows 10-11 of Table 4) and only the risk measures (rows 12-13 of Table 4). There we see that there is insignificant ex post inequality aversion, in line with the abovementioned results.

Many studies on individual risk attitudes show that women are more risk averse than men (Eckel and Grossman, 2008). In order to analyze whether there is a gender effect in our analysis, we repeated all logit regressions, now including the relevant variables multiplied by a dummy being 1 for males and 0 for females. Gender only had a significant impact in the logit regression including all variables. The estimates for this regression are given in Table 5. Men and women have similar and significant attitudes towards risks and inequalities, except for women not being significantly ex ante inequality averse or seeking. There are difference between men and women, though, in the level of their attitudes. Men are significantly less ex post inequality and collective risk seeking than women. Men are significantly less individual risk averse than women. 


\begin{tabular}{lcl}
\hline \hline Motive & Odds ratio & p-value \\
\hline Ex ante inequality $\left(\gamma_{\text {ante }}\right)$ & 0.844 & $0.049^{* *}$ \\
Ex post inequality $\left(\gamma_{\text {post }}\right)$ & 2.995 & $0.000^{* * *}$ \\
Individual risk $\left(\gamma_{\text {ind }}\right)$ & 0.261 & $0.000^{* * *}$ \\
Collective Risk $\left(\gamma_{\text {coll }}\right)$ & 1.132 & $0.000^{* * *}$ \\
\hline Ex ante inequality & 0.714 & $0.000^{* * *}$ \\
\hline Ex post inequality & 0.852 & $0.003^{* * *}$ \\
\hline Individual risk & 0.845 & $0.013^{* *}$ \\
\hline Collective Risk & 1.013 & $0.016^{* *}$ \\
\hline Ex ante inequality & 0.734 & $0.000^{* * *}$ \\
Ex post inequality & 0.948 & 0.321 \\
\hline Individual risk & 0.787 & $0.002^{* * *}$ \\
Collective Risk & 1.021 & $0.001^{* * *}$ \\
\hline \hline
\end{tabular}

Table 4: Logit estimations

\begin{tabular}{lcl}
\hline \hline Motive & Odds ratio & p-value \\
\hline Ex ante inequality $\left(\gamma_{\text {ante }}\right)$ & 0.943 & 0.648 \\
Ex ante inequality men $\left(\gamma_{\text {ante }} \times\right.$ man $)$ & 0.836 & 0.299 \\
Ex post inequality $\left(\gamma_{\text {post }}\right)$ & 5.423 & $0.000^{* * *}$ \\
Ex post inequality men $\left(\gamma_{\text {post }} \times\right.$ man $)$ & 0.390 & $0.028^{* *}$ \\
Individual risk $\left(\gamma_{\text {ind }}\right)$ & 0.132 & $0.000^{* * *}$ \\
Individual risk men $\left(\gamma_{\text {ind }} \times\right.$ man $)$ & 2.943 & $0.025^{* *}$ \\
Collective Risk $\left(\gamma_{\text {coll }}\right)$ & 1.203 & $0.000^{* * *}$ \\
Collective Risk men $\left(\gamma_{\text {coll }} \times\right.$ man $)$ & 0.907 & $0.026^{* *}$ \\
\hline \hline
\end{tabular}

Table 5: Logit estimations including gender. 


\section{Conclusion}

The literature on public risk has shown that risk and inequality are related concepts that each play a role in the decisions on how to distribute risks over groups of people. This paper reports the results of an experiment with real incentives that disentangles attitudes towards ex ante inequality, ex post inequality, individual risk, and collective risk. The results show that people are ex ante inequality and individual risk averse and ex post inequality and collective risk seeking.

While we expected ex ante inequality aversion and individual risk aversion, ex post inequality seeking and collective risk seeking were unexpected and therefore surprising. Yet, these results are in line with the results of Engelmann and Strobel (2004) who did a similar experiment in a riskless context. They also find that inequality aversion is less pronounced than expected and that the data are mostly driven by other considerations like efficiency concerns, maximin preferences, and selfishness. Moreover, when not accounting for maximin preferences, inequality aversion is highly significant.

Thus, in Engelmann and Strobel (2004) 'inequality aversion' seems to be mainly driven by maximin preferences. Similarly, in our study ex post 'inequality aversion' seems to be mainly driven by collective risk proneness. Thereby, both studies open the black box of inequality aversion and provide insights into the exact motives underlying inequality aver-

sion. They show that inequality aversion is a complex concept that has to be interpreted with care. 


\section{Appendix - Instructions of the experiment}

\section{Introduction}

Welcome to this decision-making experiment. In this experiment you can earn money. The payoffs of the participants in this experiment depend on your decisions and the decisions of other participants and random events. At the end of the experiment your earnings will be paid out privately and confidentially in cash.

It is important that you have a good understanding of the rules of the experiment. Therefore, please read these instructions carefully. In order to check that the instructions are clear to you, you will be asked a few questions at the end of the instructions. The experiment will start only after everybody has correctly answered these questions. At the end of the experiment you will be asked to fill in a short questionnaire. Thereafter, you will receive your earnings.

\section{During the whole experiment, you are not allowed to commu- nicate with other participants.}

If you have any question, please raise your hand. We will then come to you and answer your question in private.

\section{Explanation of the experiment}

In this experiment there are eleven participants, which means that there are ten other participants. The other ten participants will answer the same questions as you do, only in a different order.

The experiment consists of 30 questions and 3 practice questions. In each question you will be asked to choose between two different types of money allocations for the other participants in this experiment. Your choices will be anonymous. There are no wrong 
or right answers. We are only interested in your own preferences. During the experiment, you will not receive any information about the choices of the other participants. They will also not receive any information about your choices.

You will encounter three different types of allocations. We will now explain these three types of allocations. Note that in each question you will have to choose between two allocations.

\section{Allocation type 1}

In this experiment lotteries yield uncertain payoffs. The payoff that results from a lottery is determined by rolling a special 10-sided dice.

In the first type of allocation the ten participants will all receive the same lottery which will be played out separately for each them. Consider the following example:

\begin{tabular}{||}
\hline \hline For each of the other participants the following lottery is played SEPARATELY \\
$\qquad$\begin{tabular}{|c|c||}
\hline with probability & the participant receives \\
\hline $30 \%$ & 11.00 euro \\
\hline $70 \%$ & 6.00 euro \\
\hline
\end{tabular}
\end{tabular}

Each participant has a 30\% probability of receiving 11 euro and a 70\% probability of receiving 6 euro. This means that if the lottery of one other participant, called participant A, turns out to yield 11 euro, then the probability that another participant, called par- 
ticipant B, also gets 11 euro remains 30\%. The lotteries of different participants are thus independent and do not necessarily yield the same payoff.

\section{Allocation type 2}

In the second type of allocation the other ten participants will all receive a common lottery, which will be played once. The outcome of the lottery will be the payoff of all other ten participants. Consider the following example:

The following lottery is played $\boldsymbol{O N C E}$ and each of the other participants will
receive the payoff of this lottery
\begin{tabular}{|c|c||}
\hline with probability & all others receive \\
\hline $30 \%$ & 11.00 euro \\
\hline $70 \%$ & 6.00 euro \\
\hline
\end{tabular}

The lottery will be played once. So with a 30\% probability all other participants will receive 11 euro and with a $70 \%$ probability all other participants will receive 6 euro.

\section{Allocation type 3}

In the third type of allocation the other participants will receive a payoff for sure. They will not necessarily all receive the same payoff. We will consider two selection procedures which will determine who will receive which payoff.

Type 3a: The selection procedure is based on a random draw. Consider the following example: 


\begin{tabular}{l}
\hline \hline The computer will randomly group all other participants, who will receive \\
the following payoffs \\
$\qquad$\begin{tabular}{|c|c||}
\hline number of participants & each receives \\
\hline 3 & 11.00 euro \\
\hline 7 & 6.00 euro \\
\hline \hline
\end{tabular}
\end{tabular}

The computer will randomly select 3 people of the other participants who will receive 11 euro, while the remaining 7 other participants will receive 6 euro.

Type 3b: The selection procedure is based on the student ID number of the other participants.

The experimenter will sum all digits in the student ID number of each other participant. This number will determine the actual payoffs. The lowest numbers will receive the higher payoffs. In case two student ID numbers yield the same sum, the lower student ID number will be considered to have a lower number.

Consider the following example: 


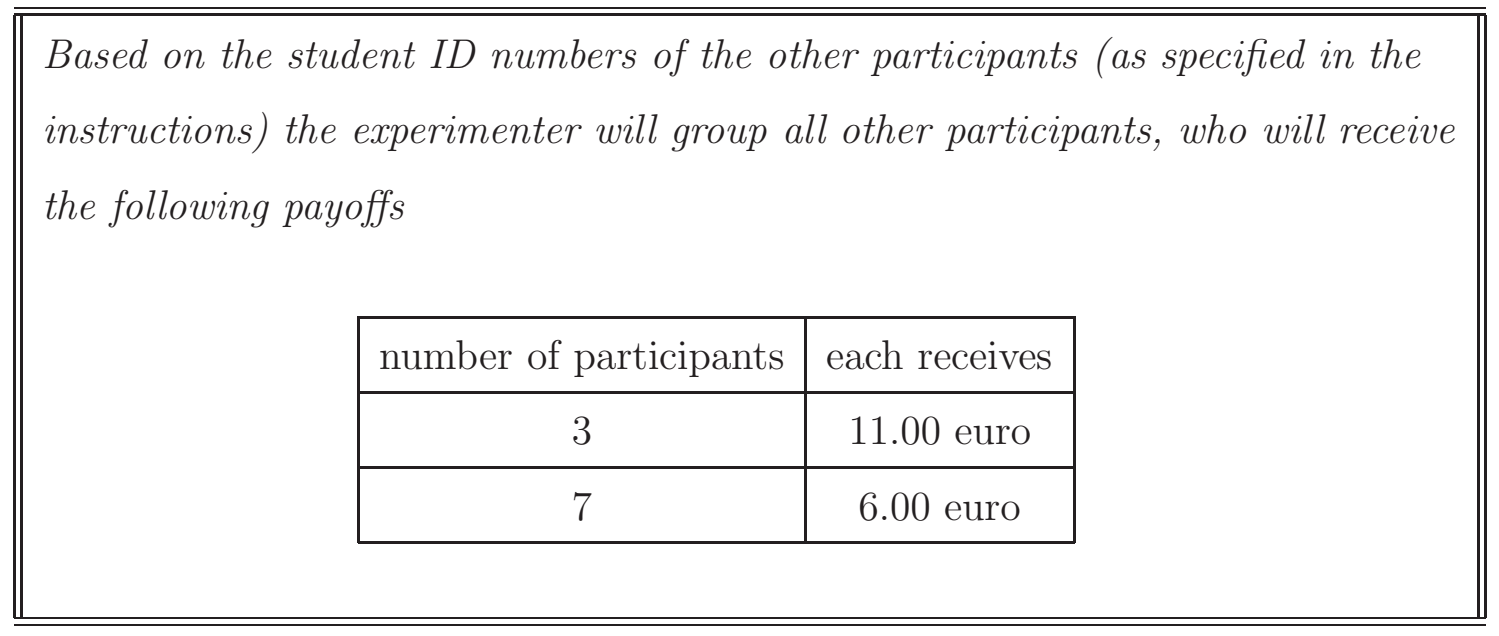

The 3 other participants with the lowest summed student ID numbers will receive 11 euro, whereas the remaining 7 other participants will receive 6 euro. 
During the experiment we will repeatedly ask you to make a choice between two allocations. The screen you will see during the experiment looks as follows.

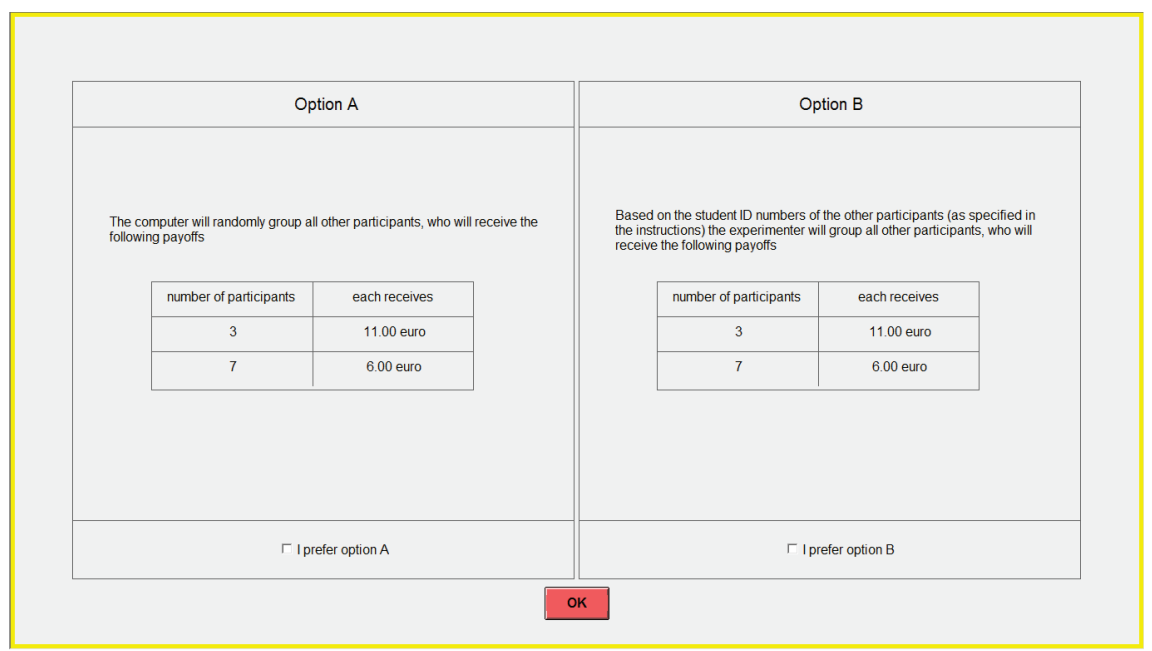

At the end of the experiment the computer will select one person out of the 11 participants at random. From that selected person, one of the questions will randomly be selected and played out for real money, to determine the payoff of all other participants. The person who is selected will earn 7.50 euro.

Your total payoff from participating in this experiment is 5 euro for showing up plus the earnings during the experiment. 


\section{Control Questions}

Please answer the following questions (you can ignore the 5 euro for showing up).

\section{Question 1}

Suppose that the computer randomly selected you at the end of the experiment. So the outcome for all other players is based upon your allocation choice. Suppose that in the question that is selected to be paid out you chose the following allocation:

For each of the other participants the following lottery is played separately

\begin{tabular}{|c|c|}
\hline with probability & the participant receives \\
\hline $30 \%$ & 11.00 euro \\
\hline $70 \%$ & 6.00 euro \\
\hline
\end{tabular}

- What will be your payoff?

- Is it possible that all other ten participants will receive 11 euro?

Please circle your answer:

YES / NO

\section{Question 2}

Suppose that the computer randomly selected one of the other ten participants at the end of the experiment. Suppose that in the question that is selected to be paid out that person chose the following allocation: 
The following lottery is played once and each of the other participants will receive the payoff of this lottery

\begin{tabular}{|c|c|}
\hline with probability & all others receive \\
\hline $30 \%$ & 11.00 euro \\
$70 \%$ & 6.00 euro \\
\hline
\end{tabular}

- Can it be the case that you will receive 11 euro and that another player receives 6 euro?

Please circle your answer:

$\mathrm{YES} / \mathrm{NO}$

\section{Question 3}

Suppose that the computer randomly selected you at the end of the experiment. So the outcome for all other players is based upon your allocation choice. Suppose that in the question that is selected to be paid out you chose the following allocation:

Based on the student ID numbers of the other participants (as specified in the instructions) the experimenter will group all other participants, who will receive the following payoffs

\begin{tabular}{|c|c|}
\hline number of participants & each receives \\
\hline 3 particpants & 11.00 euro \\
\hline 7 participants & 6.00 euro \\
\hline
\end{tabular}

- Suppose the sum of the digits of the student IDs for the other participants are as follows. 
- Please write down below the actual payoffs for these ten participants

\begin{tabular}{|c|c|}
\hline sum of digits of ID & Payoff \\
\hline 12 & \\
\hline 6 & \\
\hline 16 & \\
\hline 18 & \\
\hline 20 & \\
\hline 30 & \\
\hline 25 & \\
\hline 26 & \\
\hline 28 & \\
\hline 19 & \\
\hline
\end{tabular}

Now please raise your hand, so we can see you are done with these questions.

\section{References}

Ben-Porath, Elchanan, Itzhak Gilboa, and David Schmeidler (1997), "On the Measurement of Inequality under Uncertainty," Journal of Economic Theory, 75, 194-204.

Bian Wen-Qiang, and L. Robin Keller (1999), "Chinese and Americans agree on what is fair, but disagree on what is best in Societal Decisions affecting Health and Safety Risks," Risk Analysis, 19, 439-452.

Bolton, Gary E., Jordi Brandts, and Axel Ockenfels (2005), "Fair Procedures: Evidence from Games involving Lotteries," Economic Journal, 115, 1054-1076.

Diamond, Peter A. (1967), "Cardinal Welfare, individual ethics, and interpersonal comparision of utility: comment," Journal of Political Economy, 75, 765-766. 
Eckel, Catherine C. and Grossman, Philip J. (2008), "Men, Women and Risk Aversion: Experimental Evidence," in: Plott, Charles R., and Smith, Vernon L. (Eds.), Handbook of Experimental Economics Results, Volume 1, North-Holland, Amsterdam.

Engelmann, Dirk, and Martin Strobel (2004), "Inequality Aversion, Efficiency, and Maximin Preferences in Simple Distribution Experiments," American Economic Review, 94, 857-869.

Fischbacher, Urs (2007) "z-Tree: Zurich Toolbox for Ready-made Economic Experiments," Experimental Economics, 10, 171-178.

Fishburn, Peter C., and Rakesh K. Sarin (1991), "Dispersive Equity and Social Risk," Management Science, 37, 751-769.

Fleurbaey, Marc (2010), "Assessing Risky Social Situations," Journal of Political Economy, $118,649-680$.

Gajdos, Thibault, John A. Weymark, and Claudio Zoli (2010), "Shared Destinies and the Measurement of Social Risk Equity," Annals of Operations Research, 176, 409-424.

Greiner, B., 2004. "An Online Recruitment System for Economic Experiments," in: Kremer, K., Macho, V. (Eds.), Forschung und wissenschaftliches Rechnen 2003, GWDG Bericht 63. Ges. fr Wiss. Datenverarbeitung, Gttingen, pp. 7993.

Harsanyi, John C. (1955), "Cardinal Welfare, Individualistic Ethics, and Interpersonal Comparisons of Utility," Journal of Political Economy, 63, 309-321.

Keeney, Ralph L. (1980), "Equity and Public Risk," Operations Research, 28, 527-534.

Keeney, Ralph L., and Robert L. Winkler (1985), "Evaluating Decision Strategies for Equity of Public Risks," Operations Research, 33, 955-970.

Keller, L. Robin and Rakesh K. Sarin (1988), "Equity in Social Risk: Some Empirical Observations," Risk Analysis, 8, 135-146.

Kroll, Yoram, and Liema Davidovitz (2003), "Inequality Aversion versus Risk Aversion," Economica, 70, 19-29.

Rohde, Ingrid M.T., and Kirsten I.M. Rohde (2011), "Risk Attitudes in a Social Context," Journal of Risk an Uncertainty, 43, 205-225.

Sarin, Rakesh Kumar (1985), "Measuring Equity in Public Risk," Operations Research, 
33, 210-217.

Trautmann, Stefan T. (2009), "A tractable model of process fairness under risk," Journal of Economic Psychology, 30, 803-813. 